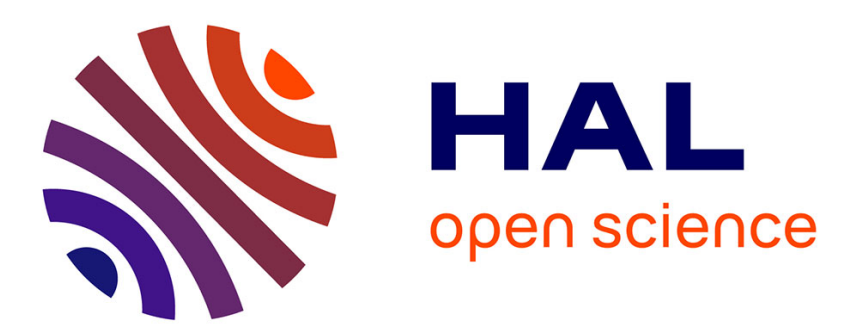

\title{
Elevages allaitants Charolais des zones herbagères face à la réforme de la PAC. Proposition d'une typologie d'adaptations et premiers résultats 1993
}

\author{
M. Lherm, D. Bébin, G. Liénard
}

\section{- To cite this version:}

M. Lherm, D. Bébin, G. Liénard. Elevages allaitants Charolais des zones herbagères face à la réforme de la PAC. Proposition d'une typologie d'adaptations et premiers résultats 1993. Productions Animales, 1994, 7 (5), pp.343-357. hal-00896096

\section{HAL Id: hal-00896096 https://hal.science/hal-00896096}

Submitted on 1 Jan 1994

HAL is a multi-disciplinary open access archive for the deposit and dissemination of scientific research documents, whether they are published or not. The documents may come from teaching and research institutions in France or abroad, or from public or private research centers.
L'archive ouverte pluridisciplinaire HAL, est destinée au dépôt et à la diffusion de documents scientifiques de niveau recherche, publiés ou non, émanant des établissements d'enseignement et de recherche français ou étrangers, des laboratoires publics ou privés. 
INRA Prod. Anim., 1994, 7 (5), 343 - 357.

\section{LHERM, D. BÉBIN, G. LIÉNARD}

INRA Laboratoire Economie de l'Elevage Theix 63122 Saint Genès Champanelle

\section{Elevages allaitants Charolais des zones herbagères face à la réforme de la PAC. Proposition d'une typologie d'adaptations et premiers résultats 1993}

- la préoccupation collective de l'entretien

Les éleveurs de bovins allaitants sont concernés par la réforme de la PAC sur trois plans différents :

- la maîtrise de l'offre de viande - celle-ci repose sur deux séries de mesures : le prix et les volumes d'intervention sont réduits progressivement de 1993 à 1996, diminution qui pourra être amplifiée par le GATT. Les compensations prévues, avec le renforcement des primes existantes sont limitées en nombre, soit par des références individuelles (cas des primes aux vaches allaitantes), soit par une référence nationale (cas des primes aux bovins mâles), à partir du nombre de primes attribuées en 1992. Un supplément extensif est créé et attribué aux exploitations les moins intensives en vue d'encourager l'extensification des systèmes.

- la maitrise des productions de céréales et oléoprotéagineux, souvent présentes en zone d'élevage allaitant - celle-ci est espérée avec la diminution du prix d'intervention des céréales, la mondialisation du prix des protéagineux et oléagineux et avec l'obligation faite aux céréaliers importants de geler $15 \%$ des surfaces de cultures. Des primes compensatoires par hectare sont créées, dont peuvent bénéficier le maïs fourrage et les céréales d'auto-fourniture, d'un montant variable selon les régions.

\section{Résumé}

La réforme de la PAC concerne les élevages de bovins allaitants dans leurs trois fonctions, de production de viande, de cultures et d'entretien de l'espace. Une typologie de situations par rapport aux modalités de la réforme est proposée à partir d'un suivi d'exploitations diverses.

Les premières adaptations réalisées en 1992 et 1993 sont présentées à partir d'un observatoire de 88 exploitations charolaises, par rapport à 1991 et elles sont resituées dans l'évolution à long terme. Les efforts des éleveurs ont d'abord été centrés, en 1992, sur la constitution du quota individuel de primes aux vaches allaitantes, avec augmentation du troupeau. En 1993, l'adaptation de l'utilisation du sol en vue d'obtenir la prime à l'herbe et les primes aux cultures ont été les principales préoccupations. En revanche, les systèmes de production des mâles sont peu changés, mais les génisses (non primées) deviennent le principal élément d'ajustement. Ces tendances risquent d'être encore vraies en 1995 . Mais l'élément majeur du développement futur dépendra de la mobilité des références par rapport aux agrandissements possibles. de l'espace. En vue d'encourager le maintien ou le développement des systèmes peu intensifs, capables d'entretenir davantage d'espace d'herbe avec le même cheptel, des mesures agri-environnementales ont été instituées, dont la principale est la prime à l'herbe, attribuée aux exploitations extensives et aux exploitations herbagères peu intensives.

Le détail des différentes mesures et la définition des seuils d'attribution des différentes primes, et leurs montants, sont rassemblés dans l'encadré 1.

La réforme arrêtée en 1992 est mise progressivement en place de 1993 à 1995-1996. De nombreuses simulations des effets de la réforme ont été réalisées, soit sur l'évolution possible des exploitations (entre autres : Bortzmeyer et al 1991, Institut de l'Elevage 1992, Benoit et al 1993), soit sur les résultats économiques sans modification de système (entre autres : Blogowski et Boyer 1994, Butault et al 1994, Bousset et Liénard 1992, Desrier et al 1994), soit sur l'importance nouvelle des aides dans la formation du revenu (Blogowski et Pascalis 1993, Hairy et de La Villosoye 1994). Elles ont toutes montré l'ampleur des changements qui affecteront le fonctionnement économique des exploitations.

Cet article analyse les premières adaptations réalisées en 1992 et 1993 par un groupe d'éleveurs charolais de la zone centrale (Nièvre, Creuse, Saône et Loire, Puy de Dôme et Allier), dont nous connaissons, pour la majorité, les trajectoires d'évolution sur une longue période (Lherm et al 1991). Il est présenté ici l'évolution, par rapport à 1991, de 88 exploitations dont on connaît les résultats pour les trois années.

Il s'agit d'exploitations en avance structurelle et technique. Ainsi, en 1991, elles disposaient en moyenne de 121 ha ( \pm 55 ha) dont $80 \%$ en fourrage, 66 vaches, 122 UGBB et 126 UGB totales, pour 2,03 UTH. Elles ne sont pas statistiquement représentatives, elles préfigurent les situations de demain. 
Les principales mesures de la Réforme de la PAC

La réforme de la PAC vise à réduire certaines productions tout en encourageant leur désintensification afin d'améliorer l'environnement et maintenir l'agriculture sur tout le territoire.

Elle prévoit la baisse des prix d'intervention des produits laitiers, de la viande bovine $(-15 \%)$ et des céréales $(-34 \%$ ) (en vue de permettre une plus grande consommation animale de ces dernières).

Elle aligne le prix des oléoprotéagineux sur les cours mondiaux. Elle oblige les "gros" producteurs de céréales (+ de 92 tonnes) à la mise en jachère d'une partie des terres labourables. En contrepartie, elle instaure des aides compensatoires :

- aides par hectare pour les céréales, les oléoprotéagineux et les surfaces de jachère (montant variable selon les rendements de références départementaux ou régionaux). Le maïs fourrage peut être compris dans les céréales primées.

- rentorcement des aides existantes, à la tête de cheptel, pour la production de viande bovine: Prime au maintien du troupeau de Vaches Allaitantes (PMTVA) et Prime aux Bovins mâles (PBM). Pour cette dernière, l'âge d'éligibilité est ramené de 12 à 10 mois et une deuxième prime est instaurée à partir de 23 mois.

La baisse des prix et l'augmentation des aides sont réalisées progressivement sur trois ans (1993 à 1995).

En outre, des quotas de Primes ("Références") sont instaurés pour chaque exploitation en PMTVA et PCO (Primes Compensatoires Ovines) - avec possibilité ultérieure de mobilité gérée administrativement (cessions, attributions, prêts). Les PBM font l'objet d'une référence nationale ; elles sont limitées à 90 par exploitation (pour chaque âge)

\section{Pour encourager la désintensification ou l'extensif}

- les Primes Vaches Allaitantes et les Primes Bovins mâles sont "plafonnées" au-delà d'une certaine "densité PAC en animaux primables" (voir ci-après) ; ce plafond baisse progressivement de 3,5 UGB primables par ha SFP en 1993 à 2 en 1996.

- un Supplément Extensif (236 F) est accordé aux vaches allaitantes et aux bovins mâles si cette même "densité PAC" est inférieure à 1,4.

- enfin, pour compenser l'avantage que représente la possibilité de déclarer le maïs fourrage dans les céréales primables, il a été instauré une "Prime à l'Herbe" pour les exploitations ayant un "chargement administratif" inférieur à 1,4 (voir ci-après). En 1993, les exploitations ayant un chargement administratif compris entre 1 et 1,4 devaient, en outre, avoir plus de $75 \%$ d'herbe (herbagères peu intensives), alors que cette proportion n'était pas exigée pour les exploitations extensives ayant un chargement inférieur à 1 .

\section{Quelques points méthodologiques}

La baisse prévue des prix et l'instauration de nouvelles aides et la majoration des anciennes bouleversent les comptes économiques. Cela a entraîné des modifications dans l'élaboration et la présentation des résultats et des indicateurs de gestion des exploitations qu'on ne peut rapporter ici dans le détail. Elles sont rassemblées dans une note méthodologique disponible auprès de notre Laboratoire (Liénard et al 1994).

Le paiement de la Prime aux Bovins Mâles est prévu en deux parties : un acompte de $60 \%$ après la déclaration et un solde de $40 \%$ dont le versement devrait être fait en Avril de l'année suivante. De même le supplément extensif (Vaches et Bovins Mâles) devrait être versé en même temps que ce solde. Nous avons considéré, comme il se devait, ces soldes comme des "créances PAC "qui ont donc été incorporées dans le produit bovin et le revenu, malgré le grand retard des paiements en 1994. L'importance de ces créances est chiffrée dans le texte.

\section{Définitions}

L'application de la Réforme repose sur des déclarations annuelles de cheptel et de surfaces. La répartition entre cultures et fourrage peut être modulée afin de satisfaire aux deux seuils précédents : le maïs fourrage et les céréales et le maïs grain peuvent être déclarés en culture ou en fourrage.

Surface fourragère déclarée : Herbe + maïs et céréales déclarés en fourrages + autres fourrages (plantes sarclées, etc)

Cultures primables ("SCOP") : Oléoprotéagineux + Céréales et maïs déclarés en culture + Jachères

Cultures non primables: Betteraves sucrières et autres

UGB primables: Vaches Allaitantes $(x 1)+$ Bovins Mâles ( $x 0,6$, si $<2$ ans et $x 1$ si $>2$ ans) + Brebis ( $x$ $0,15)+V$. Laitières $(x 1)$

UGB Primes à l'Herbe: Ensemble du troupeau herbivore présent au moment de la déclaration (donc y compris les génisses) (nécessité de conserver les vaches allaitantes ( 6 mois) et les brebis ( 5 mois environ)

Densité PAC : UGB primables par ha Surface Fourragère déclarée

Chargement administratif ou Prime à l'Herbe : UGB Prime à l'Herbe par ha Surface Fourragère déclarée

Les indicateurs de gestion habituels sont conservés pour l'analyse des exploitations. Ce sont eux qui sont indiqués dans les tableaux.

SFP Gestion = Herbe + maïs fourrage + autres fourrages annuels (ne comprend pas les céréales autoconsommées)

UGB Gestion : ensemble des Herbivores au prorata de leur temps de présence annue

Chargement Gestion (ou "Technique") : UGB Gestion par ha SFP Gestion

En élevage bovin allaitant, le chargement gestion est inférieur au chargement administratif "Prime à l'Herbe". En moyenne l'écart est de 11 à $13 \%$ pour les systèmes maigres et 8,5 à $11 \%$ pour les naisseursengraisseurs (Lherm et al 1994)

Surfaces non fourragères: Céréales (vendues et autoconsommées) + autres cultures de vente (maïs grain, oléoprétagineux et autres) + surfaces en jachère (agronomique + "industrielle").

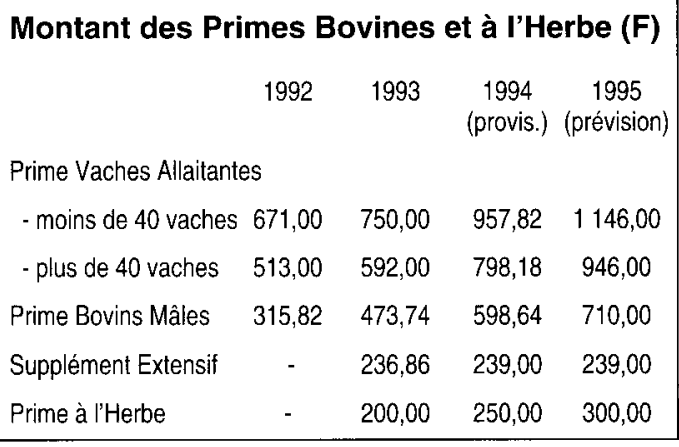


L'adaptation à la réforme de la PAC a commencé dès 1992. Elle s'est faite autour de 3 objectifs principaux : la constitution des références en primes bovines, l'obtention possible du supplément extensif et l'obtention éventuelle de la prime à l'herbe. Elle a été réalisée sur 3 plans interdépendants :

- celui des déclarations administratives

- celui de l'utilisation des surfaces

- celui des effectifs de troupeaux, et donc des ventes de l'année.

Préalablement à l'analyse des évolutions, nous présentons, en première partie, une typologie des adaptations par rapport aux principales mesures prévues par la réforme.

\section{1 / Situation des exploitations par rapport à la réforme}

La réforme et son accompagnement aboutissent à une nouvelle diversité des situations qui s'ajoute à celles repérées par la typologie classique que nous utilisons déjà, basée sur 3 axes majeurs, le système bovin principal d'après les ventes des mâles (maigres, gras, longueur du cycle), l'utilisation des surfaces (part relative des fourrages et des cultures), limportance des autres productions (notamment, en zone charolaise, les ovins et le hors-sol), axes qui doivent être complétés par d'autres (structures, degré d'intensification, utilisation des femelles).

Les exploitations sont réparties en fonction - de l'obtention de la prime à l'herbe, et du supplément extensif, et de leurs conditions d'obtention - tout en tenant compte de la gestion des cultures (gel ou pas).

La situation est codifiée par une "lettre de synthèse" selon le principe suivant :

- Type A : obtention de la prime à l'herbe, selon deux modalités : sans "renoncement" ou avec "renoncement" à d'autres primes (maïs fourrage et cultures), pour augmenter la surface fourragère administrative et donc baisser le chargement au-dessous du seuil d'obtention. "Sans renoncement" ne signifie pas qu'il n'ait pas fallu adapter les surfaces et le chargement.

- Type B : pas de prime à l'herbe. Le supplément extensif est obtenu sans difficulté.

- Type C : pas de prime à l'herbe. Le supplément extensif est obtenu avec "renoncement" (en primes cultures ou primes bovins mâles, voire en primes vaches allaitantes).

- Type D : pas de prime à l'herbe ni de supplément extensif.

Les deux types $A$ et $B$ sont subdivisés en $A / A$ ' et $B / B$ ', en fonction de l'importance de l'herbe, de part et d'autre du seuil de $75 \%$, qui conditionne son obtention (figure 1).

S'ajoute à ces caractéristiques la stratégie concernant le gel, que certains éleveurs ont préféré éviter, soit en limitant les surfaces de
Figure 1. Répartition des exploitations Charolaises par rapport à la réforme de la PAC (1993).

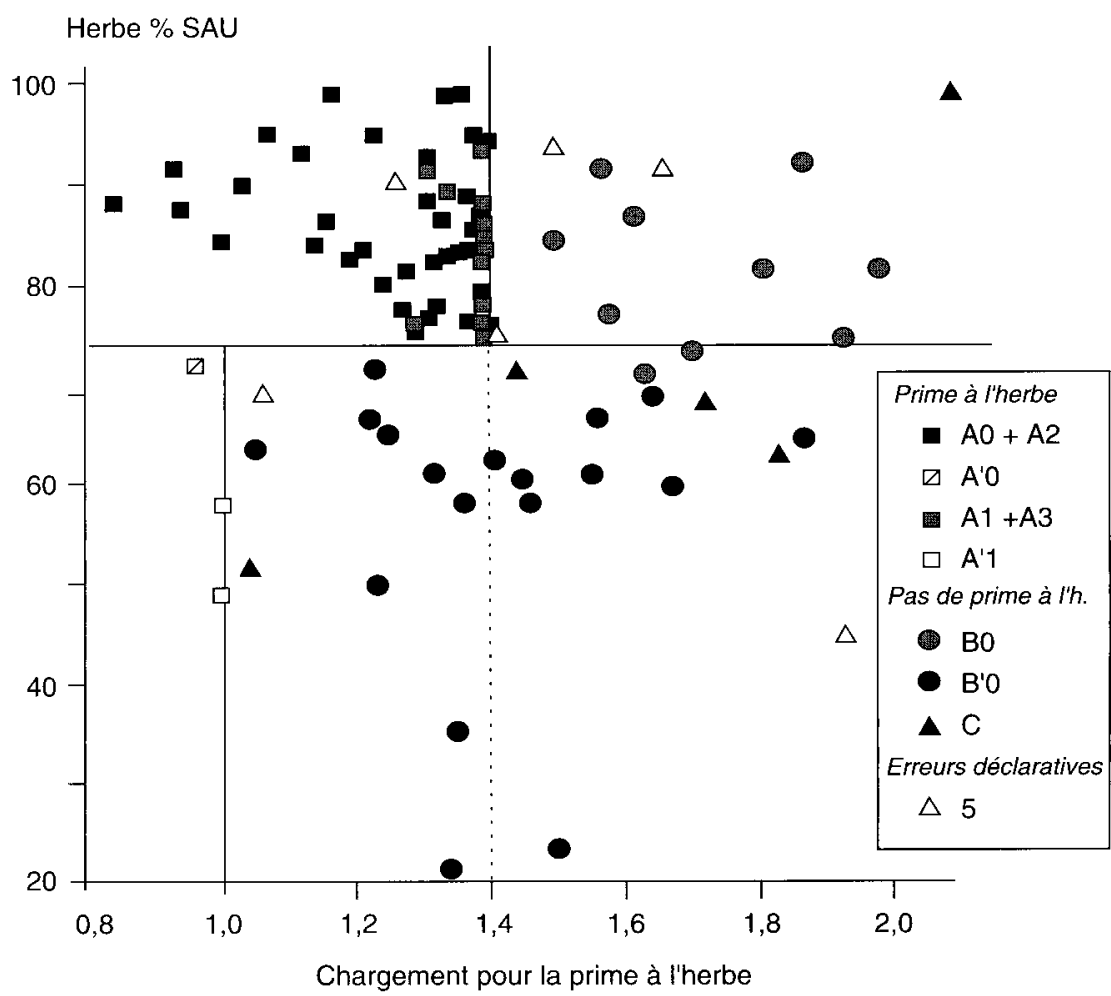

céréales déclarées, soit en renonçant aux oléoprotéagineux.

Les différents "renoncements" aux primes cultures (maïs fourrage inclus) sont repérés par des chiffres :

0 pas de renoncement

1 renoncement pour la prime à l'herbe

2 renoncement pour éviter le gel

3 renoncement pour les deux à la fois

Le code 4 correspond au double renoncement, en primes cultures et primes animales, pour obtenir le supplément extensif. Les réductions de primes par erreur déclaratives sont codées 5 .

Le tableau 1 résume l'ensemble des situations possibles et donne la répartition des 93 exploitations suivies en 1993 . On peut constater qu'il y a peu d'exploitations de type C (supplément extensif obtenu avec difficulté) dans l'échantillon, comme plus généralement en zone charolaise. Aucune n'a été exclue du supplément extensif (type $\mathrm{D}$ ), situation très rare en zone herbagère, mais le cas se rencontre dans les zones intensives de l'Ouest.

Pour la suite de l'étude nous avons regroupé les exploitations par rapport à la prime à l'herbe (en ne retenant pas celles qui ont bénéficié d'un contrat d'extensification, ni celles de type $\mathrm{C}$, ni celles dont on ne connaît pas l'évolution depuis 1991, soit 76 exploitations):

1) celles qui ont bénéficié de la prime à l'herbe "sans renoncement", il s'agit des types A0 et A'0, A2 et A'2, A5 et A'5 ; soit 30 exploitations désignées par la suite comme "PH sans concessions".
Les exploitations sont dans différentes situations par rapport aux principales mesures de la réforme de la PAC. La typologie proposée permet de les caractériser. 
Tableau 1. Typologie des exploitations par rapport à la réforme de la PAC

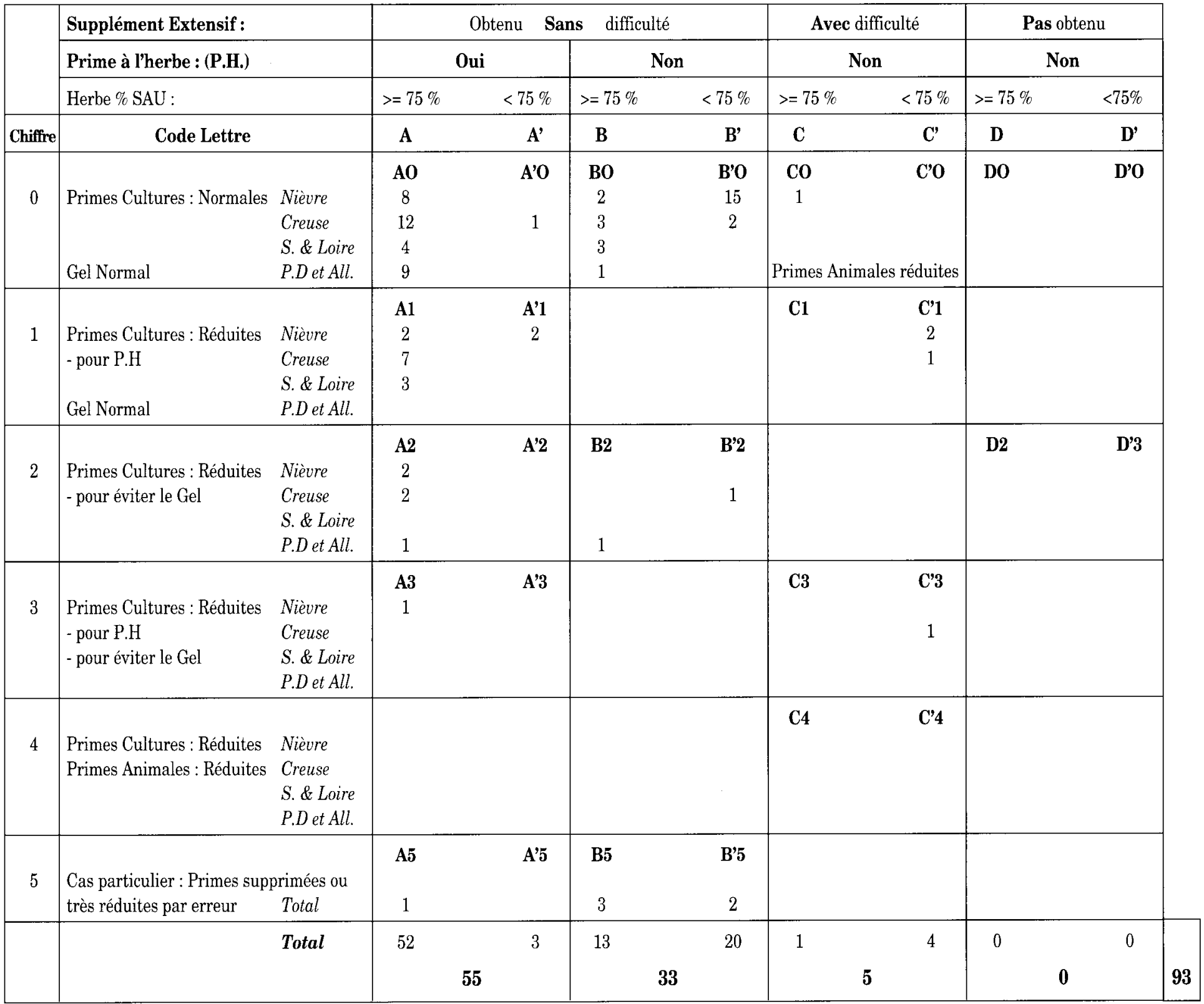

2) celles qui ont obtenu la prime à l'herbe avec des "renoncements" : il s'agit des types A1 et A'1, A3 et A'3 ; soit 15 exploitations, désignées par la suite comme "PH avec concessions".

3) celles qui en ont été exclues parce qu'elles étaient trop chargées, alors qu'elles avaient plus de $75 \%$ d'herbe : il s'agit des types B0, B2 et B5; soit 12 exploitations désignées comme "herbagers intensifs".

4) celles qui en ont été exclues parce qu'elles n'avaient pas assez d'herbe, tout en ayant un chargement administratif supérieur à 1 : il s'agit des types B'0, B'2 et B'5; soit 19 exploitations désignées comme "mixtes fourrages-céréales".

Au total, $59 \%$ des exploitations ont obtenu la prime à l'herbe, dont $27 \%$ avec "renoncement" à d'autres primes. En Nièvre, où les exploitations sont plus céréalières, $43 \%$ seulement l'ont eu, dont un tiers avec renoncement. Les obligations de gel concernaient $44 \%$ des exploitations (effet structures de l'échantillon) et $34 \%$ ont dû le faire, (70\% en Nièvre, $19 \%$ en Creuse), les autres ayant renoncé à une partie de leurs primes cultures pour l'éviter (types 2 et 3 ).

Ce décompte illustre la méthodologie. Bien que non statistiquement représentatif, il montre la diversité, et notamment l'existence d'exploitations charolaises concernées par les contraintes cultures. L'intérêt de l'échantillon observé est de comporter beaucoup d'exploitations qui ont un chargement proche du seuil administratif de 1,40 (correspondant à un 
chargement gestion de l'ordre de 1,25 - cf encadré), et où les choix étaient ouverts. Les éleveurs ont su mettre à profit les souplesses marginales du système déclaratif. Mais beaucoup de décisions prises engagent l'avenir (telles celles attachées à la prime à l'herbe, prises pour 5 ans) sans qu'ils aient tous les éléments d'appréciation (évolution possible des règles, de la situation économique, des structures foncières, etc).

Parmi les 93 exploitations, 6 ont perdu des primes cultures par méconnaissance ou erreur, même dans ce groupe en principe mieux informé que l'ensemble.

\section{2 / Les adaptations structurelles}

Sur le long terme, l'agrandissement est entrepris depuis longtemps dans ces exploitations, et il se poursuit (figure 2). L'utilisation des hectares repris differe selon les lieux : en Nièvre la proportion des cultures augmente (de 21 à $30 \%$ de 1978 à 1991, en échantillon constant), ailleurs, elle se maintient au plus (Creuse $15 \%$ ). Le chargement n'augmente plus depuis 1983-1984 et se stabilise dans l'échantillon vers 1,25 UGB/ha SFP jusqu'en 1990 ; il tend néanmoins à réaugmenter en 1991/1992 (pousse d'herbe plus favorable) jusqu'à une moyenne de 1,30 UGB/ha SFP en 1992. L'augmentation des effectifs de troupeau suit celle des surfaces, en fonction de l'orientation fourragère (figure 3 ).

En 1993, l'agrandissement s'est amplifié ( $+6,8$ ha, $+5,5 \%$ en moyenne d'ensemble). On ne peut attribuer cette accélération à la seule réforme de la PAC. En revanche, l'utilisation des surfaces supplémentaires est directement influencée par ses contraintes, tout comme l'évolution du cheptel et du chargement. Deux éléments ont été déterminants et parfois en contradiction :

- la constitution du maximum de références en primes vaches allaitantes, ceci dès 1992 ; il faut donc analyser les évolutions à partir de 1991. Cette recherche a concerné la quasi totalité des éleveurs, mais elle doit être resituée par rapport aux effectifs déjà atteints (qui sont ici élevés) et aux objectifs des éleveurs (âge, stade de développement, perspectives successorales, etc).

- la possibilité ou non d'obtenir la prime à l'herbe.

\section{1 / La constitution des références en primes vaches allaitantes}

Globalement, le phénomène est net. Il est résumé, pour les 88 exploitations, dans le tableau 2. En 1992, les éleveurs augmentent à la fois le troupeau de mères et le nombre de vêlages, dans le prolongement de 1989/1991. Ils cherchent aussi à obtenir davantage de références en tirant partie des dates de déclaration possibles (on pouvait choisir entre le 30 septembre et le 31 décembre, cette dernière
Tableau 2. Evolution du troupeau bovin et du nombre de primes au maintien du troupeau de vaches allaitantes (PMTVA) de 1991 à 1993.

\begin{tabular}{|c|c|c|c|c|c|}
\hline Année & $\begin{array}{c}\text { PMTVA } \\
\mathrm{Nb}\end{array}$ & $\begin{array}{c}\text { Vélages } \\
\mathrm{Nb}\end{array}$ & $\begin{array}{c}\text { Taux annuel } \\
\text { d'accroissement } \\
\text { du nombre de vaches } \\
\text { (fin - début) \% }\end{array}$ & $\begin{array}{c}\text { Effectif } \\
\text { moyen } \\
\text { vaches }\end{array}$ & $\begin{array}{c}\text { UGBB } \\
\text { moyen } \\
\mathrm{Nb}\end{array}$ \\
\hline 1991 & 66,0 & 69,4 & $+3,9$ & 66,6 & 121,7 \\
\hline 1992 & $\begin{array}{l}72,4 \\
(+10 \%)\end{array}$ & $\begin{array}{l}72,5 \\
(+4,5 \%)\end{array}$ & $+2,5$ & $\begin{array}{l}69,6 \\
(+4,5 \%)\end{array}$ & 125,5 \\
\hline 1993 & $\begin{array}{l}72,3 \\
(-0,2 \%)\end{array}$ & $\begin{array}{l}74,7 \\
(+3,0 \%)\end{array}$ & $+3,4$ & $\begin{array}{l}71,7 \\
(+3,0)\end{array}$ & 128,0 \\
\hline
\end{tabular}

Figure 2. Evolution à long terme des surfaces par travailleur dans des échantillons constants d'exploitations Charolaises.

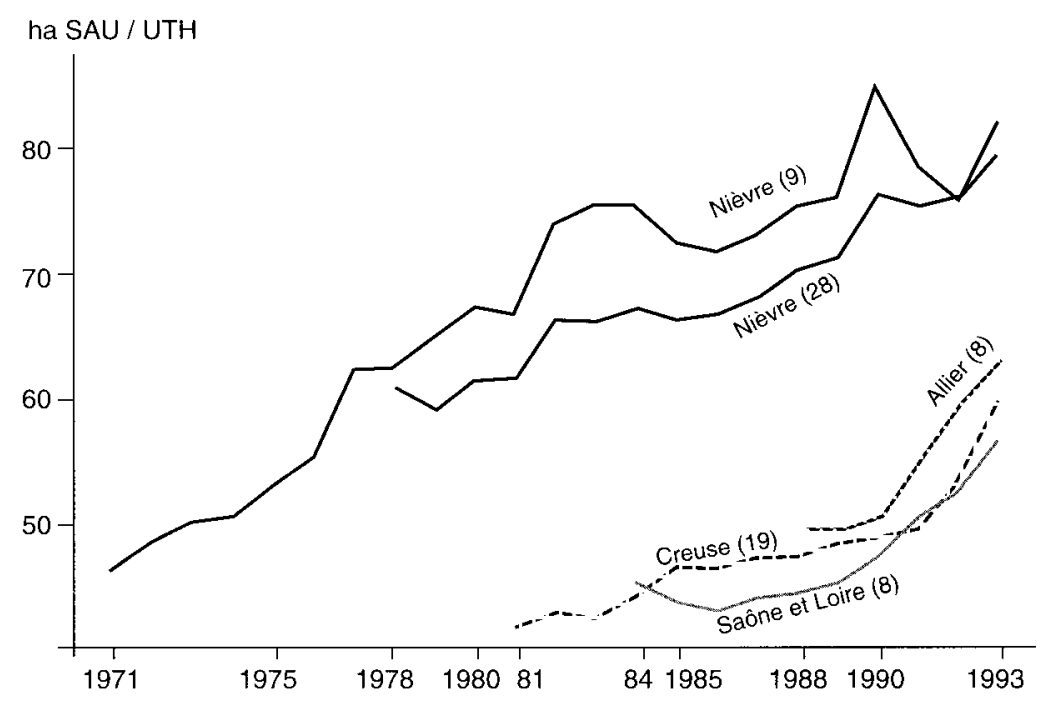

Figure 3. Evolution à long terme des effectifs de troupeau par travailleur dans des échantillons constants d'exploitations Charolaises.

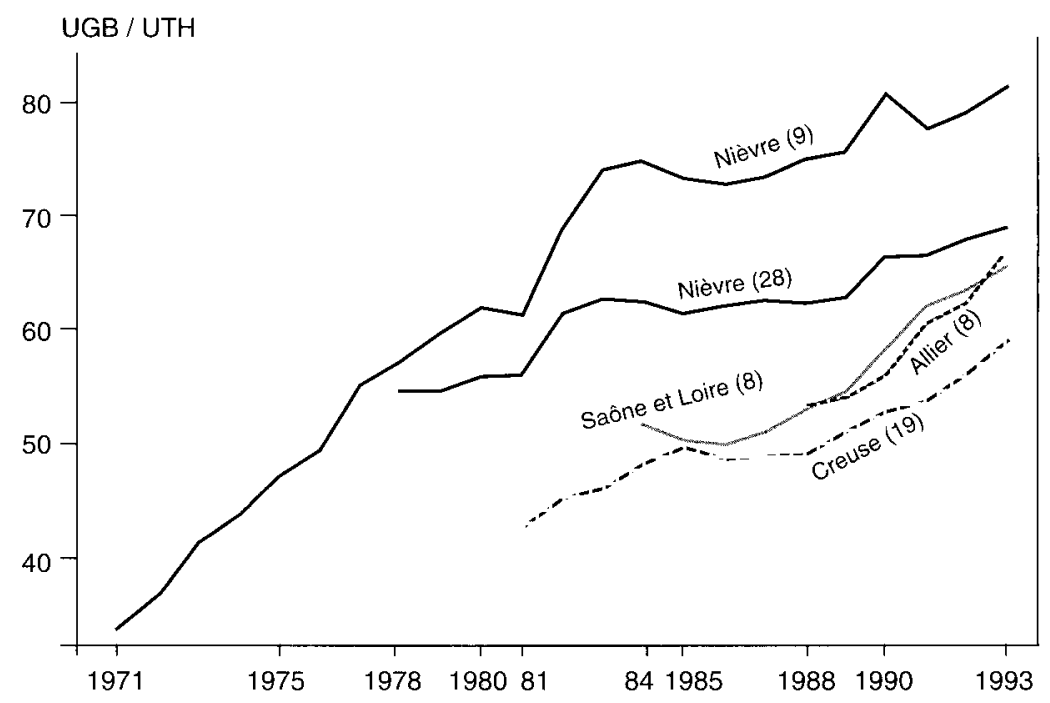

date permettant de déclarer les primipares vêlant en fin d'année, qui sont de plus en plus nombreuses).

En 1993, les références individuelles doivent, selon les textes, être réduites de $3 \%$, sauf attribution supplémentaire. Dans le groupe, elles ne diminuent que de $0,2 \%$, car cer- 
Figure 4. Evolution à long terme du revenu du travail et des capitaux propres d'exploitation par travailleur dans des échantillons constants d'exploitations Charolaises.

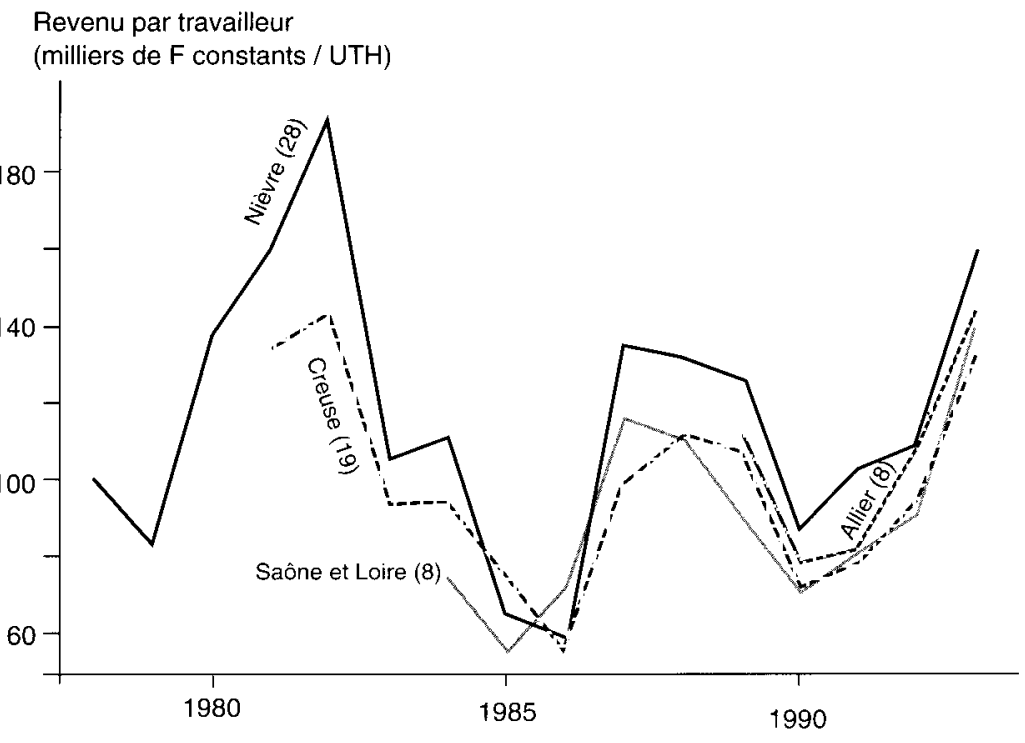

tains ont obtenu des suppléments ou des prêts, notamment en Creuse, où il y a beaucoup de départs à la retraite. La croissance de l'effectif de vaches n'en est pas arrêtée pour autant. Elle se poursuit en 1994 , car fin 1993 , le nombre de vaches est supérieur de $3,4 \%$ par rapport à janvier. La conjoncture bovine favorable de 1993/1994 a incité à poursuivre l'augmentation au-delà des références. Mais ce ne sera plus le cas lorsque la conjoncture se retournera. On voit l'importance d'une bonne mobilisation des références disponibles.

L'augmentation de l'effectif de vaches $(+3,7 \%$ par an, en moyenne sur deux ans) ne s'est pas réalisée, dans ces grands troupeaux, par achat de vaches ou de génisses pleines mais par croît interne; alors que dans notre réseau concerté Allier (avec Cemagref et Chambre d'Agriculture de l'Allier), les achats de vaches ont été multipliés par 10 (Bousset et al 1994). La quasi totalité des exploitations a augmenté à la fois les effectifs de troupeaux et les primes vaches allaitantes. Il n'y a pas de différences selon les systèmes de production (bœufs et broutards, mêmes proportions). On peut en revanche nuancer un peu selon les contraintes qu'a pu imposer la prime à l'herbe. Mais, comme on le verra, l'adaptation pour réduire le chargement s'est faite au détriment des autres catégories d'animaux, notamment des génisses.

\section{2 / Les surfaces, le chargement et la prime à l'herbe}

L'analyse est faite selon les regroupements d'exploitations par rapport à la prime à l'herbe définis dans le paragraphe 1 .

\section{a / Les bénéficiaires de la prime à l'herbe}

L'agrandissement a été, en moyenne, important $(+7,1$ ha SAU en 1993 , pour 118 ha en 1992), et il a été consacré en quasi totalité à la SFP et à l'herbe (+ 6,5 ha). Il n'y a pas de diffé- rence entre ceux qui ont eu la prime à l'herbe sans concessions ou avec concessions (figure 5).

La différence entre les deux catégories réside évidemment dans les chargements, en relation avec la surface, la main d'oeuvre, la localisation. En 1991, les "PH sans concessions" ont davantage de surface que ceux qui l'ont eu avec concession (118 ha contre 110 ) ; ils ont aussi un peu moins de main d'œuvre ( 2 UTH contre 2,13). Ils sont un peu plus spécialisés (87\% de SFP contre $82 \%$ ), entretiennent un troupeau guère plus nombreux (123 UGB contre 120), mais avec un chargement moindre $(1,19$ UGB par ha SFP contre 1,32$)$. En revanche les systèmes bovins diffèrent peu (60\% de systèmes maigres chez les premiers ; $47 \%$ chez les seconds).

En 1993, contrairement à ce qu'on pouvait attendre, les "PH avec concessions" ne consacrent pas la totalité de leur agrandissement $(+7,4$ ha) aux fourrages, ce qui aurait facilité la réduction du chargement. Ils maintiennent les cultures à $15 \%$ de la SAU, le maïs est un peu réduit (à $5,2 \%$ de la SFP), mais le cheptel est augmenté $(+6,2$ UGB entre $1992 / 1993$ et +9 UGB depuis 1991), et le chargement ne diminue pratiquement pas, il reste à $1,30 \mathrm{UGB} / \mathrm{ha}$ SFP. Clairement, la prime à l'herbe a été obtenue, un peu avec l'herbe supplémentaire $(6,6 \mathrm{ha})$, beaucoup avec le renoncement à des primes cultures : $87 \%$ du maïs et $30 \%$ des céréales ne sont pas primés.

En revanche chez les "PH sans concessions", la quasi totalité de l'agrandissement (6,8 ha) a été consacrée à l'herbe (6,3 ha), accentuant leur spécialisation fourragère ( $88 \%$ de SFP). Le troupeau augmente beaucoup moins (2,6 UGB, au détriment des ovins), le chargement baisse sensiblement (à $1,16 \mathrm{UGB} / \mathrm{ha}$ SFP) alors qu'on satisfait déjà au seuil administratif (cf encadré). La quasi totalité des surfaces de maïs et céréales est primée. Ainsi, ils n'ont pas mis à profit la possibilité qu'ils pouvaient avoir d'augmenter un peu les cultures primables. Au contraire, ils ont accentué leur caractère herbager.

\section{b / Les exclus de la prime à l'herbe}

Les "herbagers intensifs", exclus pour motif de chargement (> 75\% d'herbe).

En 1991, avec 107 ha et beaucoup de maind'œuvre $(2,12)$, les éleveurs consacrent $88 \%$ de la SAU aux fourrages et entretiennent 142 UGB avec un chargement très élevé (1,52 UGB/ha SFP). La moitié engraisse (taurillons d'auge, boufs), l'autre moitié vend en maigre (broutards d'automne surtout).

En 1993, l'agrandissement est faible (2,5 ha sur 1992), 1/4 est consacré aux cultures dont la proportion s'accroît un peu (figure 5). Le troupeau augmente beaucoup en 1992, et encore un peu en 1993, sur les 2 ans, près de $9 \%$. Ainsi, le chargement reste élevé (1,50 UGB/ha SFP). Comme on pouvait l'escompter, la quasi totalité du maïs fourrage et des cultures est primée $(95 \%)$. Ces exploitations restent très intensives, parfois à la limite du raisonnable, 
Figure 5. Evolution 1991-1993 des surfaces, du chargement et des effectifs des troupeaux par travailleur dans les exploitations bénéficiant ou non de la prime à l'herbe.

$\begin{array}{cccc}\text { Prime à l'herbe sans } & \text { Prime à l'herbe avec } & \text { Sans prime à l'herbe } & \text { Sans prime à l'herbe } \\ \text { concession } & \text { concession } & \text { avec plus de } 75 \% & \text { avec moins de } 75 \% \\ \text { (30 exploitations) } & \text { (15 exploitations) } & \text { (12 exploitations) } & \text { (19 exploitations) }\end{array}$
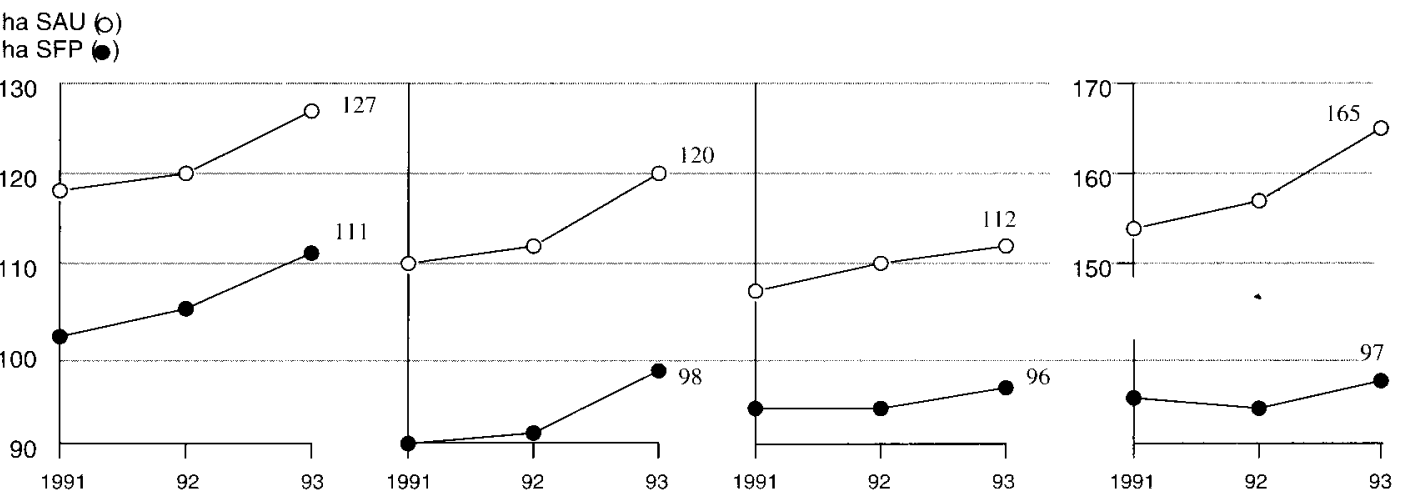

Chargement $P$ )

UGB / ha SFP

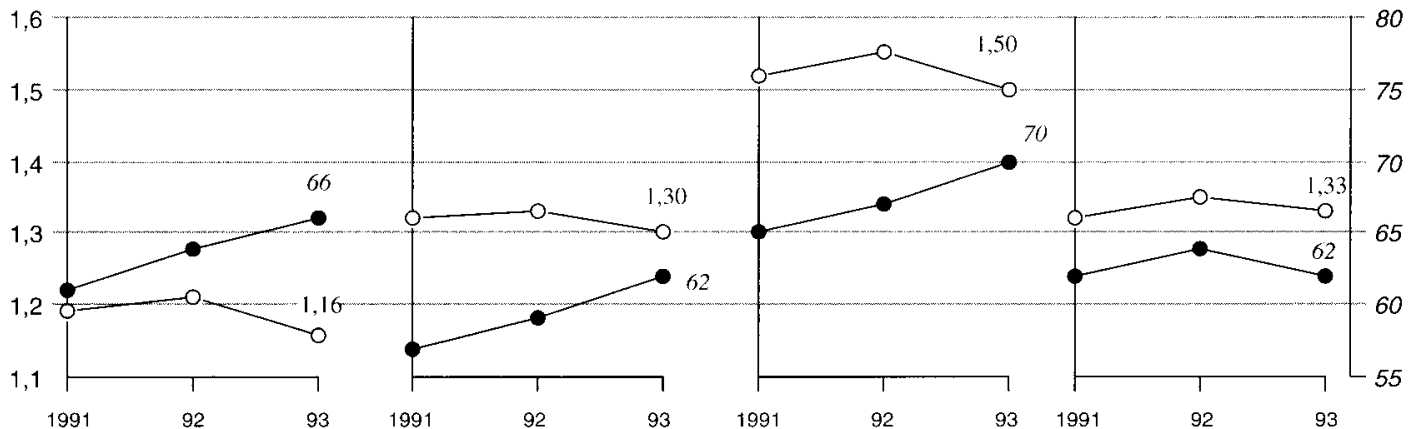

mais elles entretiennent 70 UGB par travailleur (contre $65 \mathrm{chez}$ les bénéficiaires de la prime à l'herbe), car il y a davantage de jeunes, d'investissements et d'endettement (1 $100 \mathrm{~F}$ d'annuité par hectare, contre $850 \mathrm{~F}$ chez les bénéficiaires de la prime à l'herbe.)

Elles restent "à l'affût" des possibilités de pouvoir en bénéficier. Avec un agrandissement, elles rejoindraient la stratégie de ceux qui l'ont obtenu avec concession sur les primes cultures, mais il faudrait que la pression foncière le permette, et que la législation l'autorise (3 sur 12 l'aura en 1994, par un agrandissement).

Les "mixtes fourrages-céréales" $(<75 \%$ d'herbe).

En 1991, il s'agit des plus grandes exploitations (154 ha, avec 2,08 UTH), Nivernaises pour la plupart (15 et 4 en Creuse).

Les cultures non fourragères occupent $38 \%$ de la SAU. Le troupeau est cependant important (127 UGB), avec un chargement assez élevé (1,32 UGB/ha SFP). Il y a là autant de naisseurs (broutards céréaliers de la Nièvre) que d'engraisseurs (taurillons d'auge et taurillons herbagers intensifs de 20 mois).

L'agrandissement est important, près de 11 ha en 2 ans, il est consacré aux $2 / 3$ aux cultures, dont l'importance est renforcée $(41 \%)$ (figure 5). Le troupeau augmente, essentiellement entre 1991 et 1992 , plus modérément que dans les autres types (5,3 UGB et $4 \%$ en 2 ans). Visiblement "on a fait le plein en travail" (62 UGB et 32 ha de culture par UTH). Le chargement reste inchangé $(1,33 \mathrm{UGB} / \mathrm{ha}$ SFP). La quasi totalité des cultures et du maïs fourrage est primée $(95 \%)$, mais il y a plus de 10 ha de gel par exploitation ( $6 \%$ de la SAU).

Manifestement, les préoccupations sont différentes, notamment en Nièvre. Mais, on le verra, c'est dans ces exploitations que le revenu évolue le moins favorablement.

\section{3 / Quels changements dans les systèmes d'élevage?}

Sur le long terme, ces exploitations charolaises se caractérisent par un avancement continu des dates de vêlages, avec pour certaines, de plus en plus de vêlages d'automne, par une diminution de l'engraissement, du moins en Nièvre, et par un raccourcissement du cycle de production. Pour les mâles, le raccourcissement s'est fait au profit de deux catégories : les broutards d'hiver et les taurillons d'auge qui représentent chacun $20 \%$ des ventes en 1991 ; il s'est réalisé, en maigre, au détriment des animaux âgés (20 mois et plus) car les broutards d'automne se maintiennent (à $15 \%$ des ventes), en engraissement au détriment des bœufs puis des taurillons herbagers de 20-24 mois. De même, si l'engraisse-
En 1993, le chargement diminue dans toutes les exploitations et les surfaces continuent d'augmenter, essentiellement en SFP pour les bénéficiaires de la prime à l'herbe 
ment des vaches se maintient, du moins dans l'échantillon (65\% des ventes en 1991), celui des génisses (33\% en 1991) est en déclin depuis 1988 (interdiction des anabolisants), sauf en Creuse grâce à un groupement de producteurs très actif.

Globalement, et pour l'ensemble des exploitations, 1992 et 1993 voient ces tendances se poursuivre sans grande inflexion pour les mâles, avec une nouvelle réduction de l'engraissement au profit des broutards d'hiver ( $24 \%$ des ventes). Les maigres âgés et les taurillons herbagers diminuent encore, alors que les broutards d'automne et les taurillons d'auge se maintiennent (respectivement à 15 et $21 \%$ ). Donc pas de rupture réelle sous l'effet de la réforme. C'est le marché et les considérations de situations individuelles qui sont restés les éléments directeurs.

Les ventes de femelles ont été beaucoup plus perturbées, en relation avec la constitution des références. Paradoxalement, dans l'échantillon, les ventes de vaches sont globalement plus nombreuses. Ainsi, le taux de réforme n'est pas réduit en 1992 ni en 1993. On engraisse un peu moins de vaches, mais les ventes de vaches maigres et d'élevage augmentent fortement $(+36 \%$ en $1992,+47 \%$ en 1993, par rapport à 1991), en réponse à la demande du marché créé par le renforcement des troupeaux allaitants ailleurs. Ces grands troupeaux, qui disposent d'un gros réservoir de génisses, ont pu vendre des vaches sans nuire à leur propre croissance.

Les changements les plus amples apparaissent dans les ventes de génisses. Les ventes de laitonnes (7-10 mois) doublent en 1992 et 1993, par rapport à 1991 ; celles de broutardes d'hiver (11-14 mois) augmentent de $55 \%$ en 1992. En revanche, les ventes de génisses plus âgées sont peu modifiées, même en 1993 alors que leurs prix sont en hausse de $1000 \mathrm{~F}$ par tête. Visiblement, ce sont les génisses les plus jeunes qui ont fourni les ajustements nécessaires, en vue de réduire éventuellement le chargement et de faire face aux problèmes de places et de trésorerie.

Quels ont pu être les effets de la prime aux bovins mâles ?

Fin 1992, la prime aux bovins mâles est attribuable à partir de 10 mois au lieu de 12 , ce qui concerne en premier lieu les broutards. En 1993, une deuxième prime est attribuable à partir de 23 mois. Le montant augmente à partir du ler janvier 1993 (de 316 à $473 \mathrm{~F}$ ) ce qui incite à reporter sur 1993, mais la référence nationale était basée sur 1992 et on craignait un peu une référence individuelle...(d'où dilemme !)

Les simulations faisaient apparaître l'intérêt du vieillissement des broutards au-delà de 10 mois, et l'intérêt tout aussi grand “d'aller chercher la 2 ème prime" en prolongeant l'engraissement au-delà des 23 mois (taurillons herbagers, voire bœufs).

En 1993, ce type d'évolution est très peu visible, du moins dans l'échantillon. Certes, par rapport à 1991 , le nombre de primes "prises en compte" augmente de 1,5\% en 1992 , et de $51 \%$ en $1993^{(1)}$. Mais l'essentiel de ce doublement provient, non du changement de production des mâles, mais des modalités d'attribution à système inchangé.

Quatre effets se cumulent en effet :

- l'attribution de la 2ème prime aux taureaux de 2 ans et aux bœufs déjà produits auparavant. Néanmoins leur nombre n'augmente pas par rapport à 1991. Et il n'augmentera pas en 1994 , car il y a moins de mâles de 18 mois présents au 31 décembre 1993 qu'au ler janvier 1992.

- une demande plus systématique de ces primes par les éleveurs.

- l'attribution nouvelle aux broutards qui étaient déjà vendus entre 10 et 12 mois (14\% des ventes de broutards en 1992).

- le vieillissement au-delà de 10 mois des broutards précédemment vendus plus jeunes ; mais celui-ci a été très peu pratiqué en 1993, puisqu'il ne concerne que $8 \%$ du total des broutards vendus.

Le "peu d'effet incitatif apparent" de la prime aux bovins mâles en 1993 a plusieurs origines :

- en 1993, son montant reste encore relativement modeste. Et le supplément extensif qui contribue à sa revalorisation (236 F) est encore lointain ; il devait être réglé en avril 1994 , avec le solde $(40 \%)$ de la prime bovins mâles (en juillet 1994, il n'est pas encore versé). Et il n'est donc guère présent dans les calculs des éleveurs, sauf de ceux qui étaient en limite de le recevoir (type C).

- les cours des broutards d'automne en début de campagne de commercialisation (août à octobre 1993) ont été élevés et n'ont pas incité au report.

- la prise en compte des bovins mâles, comme des génisses d'ailleurs, dans le cheptel déclaré en début d'année en vue du calcul du chargement administratif, en fait un élément d'ajustement pour ceux qui sont en limite. Car il n'est pas question de réduire les vaches ou de risquer la perte de la prime à l'herbe et la préférence est clairement donnée à la vente des broutards (et des laitonnes), ou de la génération suivante, avant la fin janvier. Ceci freine l'allongement du cycle de production des mâles chez ceux qui ne le pratiquent pas, du moins à surface constante. En cas d'agrandissement, tout dépendra des références en primes vaches allaitantes que l'on pourra obtenir.

Ainsi, il n'y a pas eu de véritable changement des systèmes d'élevage des mâles contrairement à ce que certaines simulations avaient fait pressentir (Bortzmeyer et al 1992, Institut de l'Elevage 1992). Mais le phénomène de vieillis-

\footnotetext{
1) Il ne faut pas sous-estimer les difficultés que représente "la prise en compte» des primes bovins mâles, dont l'acompte $60 \%$ n'est touché que plusieurs mois après la demande et la vente... Et on peut faire jusqu'à 5 séries de demandes dans l'année. Nous avons considéré les primes bovins mâles reçues dans l'exercice, avec le supplément extensif afférent (voir encadré).
} 
sement des broutards apparaîtra davantage en 1994 puisque quelques producteurs nivernais de broutards-céréales ont augmenté leurs reports sur 1994. De fait, il faudra attendre la fin de la mise en place de la réforme, en 19951996, pour juger de l'ampleur réel des changements dans les systèmes d'élevage des mâles. En effet, les primes seront alors à leur maximum, tant pour les bovins que pour les cultures ; le nombre de primes bovines par hectare (densité $\mathrm{PAC}$, cf encadré), sera ramené de 3,5 à 2 , et cela pourra réduire l'intérêt des engraisseurs vis-à-vis des premières primes bovins mâles. Mais, surtout, le marché aura pu évoluer d'ici là, et c'est lui l'élément directeur final.

\section{4 / Impact économique}

\section{1 / Des marges bovines et fourragères améliorées}

L'année 1993 a vu se cumuler les nouvelles primes aux bovins et aux fourrages avec un quasi maintien de la conjoncture bovine; le prix de vente moyen toutes catégories augmente de $3,5 \%$ par rapport à 1992 (en francs courants).

En outre, les résultats techniques bovins progressent légèrement : pour l'ensemble des 88 exploitations la production autonome s'améliore de $4,5 \%$ (de 243 à $254 \mathrm{~kg} / \mathrm{UGB}$ ), pour $40 \%$ grâce à l'augmentation de la productivité et pour $60 \%$ grâce à la réduction des concentrés (kg et prix, - $5 \%$ chacun). Globalement la marge bovine finale sans aides s'améliore de 320 F/UGB. Les aides bovines augmentent de $307 \mathrm{~F}(+20 \%)$, dont $218 \mathrm{~F}$ de créances (cf encadré). La marge bovine finale avec les aides, atteint $3624 \mathrm{~F}$ par UGB, en hausse de $627 \mathrm{~F}(+20 \%$; sans les créances $+14 \%)$. Année exceptionnelle.

Les augmentations des primes et marges par UGB diffèrent peu entre les systèmes de production des mâles. La figure 6 rassemble les aides bovines PAC par UGB et par système, pour la Creuse et la Nièvre. Le montant de la prime vache allaitante diminue avec la longueur du cycle, en 1993 comme en 1992. En 1992, la prime bovins mâles ne compensait qu'en partie ; notamment les cycles les plus longs (taurillons herbagers de 2 ans, bœufs) obtenaient un montant inférieur (de 80 à $100 \mathrm{~F}$ par UGB) par rapport aux broutards et taurillons d'auge, autour d'une moyenne de 425 F/UGB. En 1993, la deuxième prime bovins mâles compense en cycles longs. Et le montant total des primes bovines PAC ne diffêre plus beaucoup entre les systèmes, de 630$690 \mathrm{~F}$ par UGB en broutards d'automne à $700 \mathrm{~F}$ pour les bœufs et $700-730$ pour les maigres de 18 mois. Les écarts supplémentaires observables entre les exploitations proviennent de l'importance plus ou moins grande des génisses (non primées) dans le troupeau, et des mâles dont la demande de prime a pu être reportée sur l'année suivante.

Ainsi, les écarts de marge bovine par UGB qui peuvent subsister entre les systèmes (et les
Figure 6. Marges et aides bovines par UGB bovine en 1992 et 1993, selon les systèmes de production.

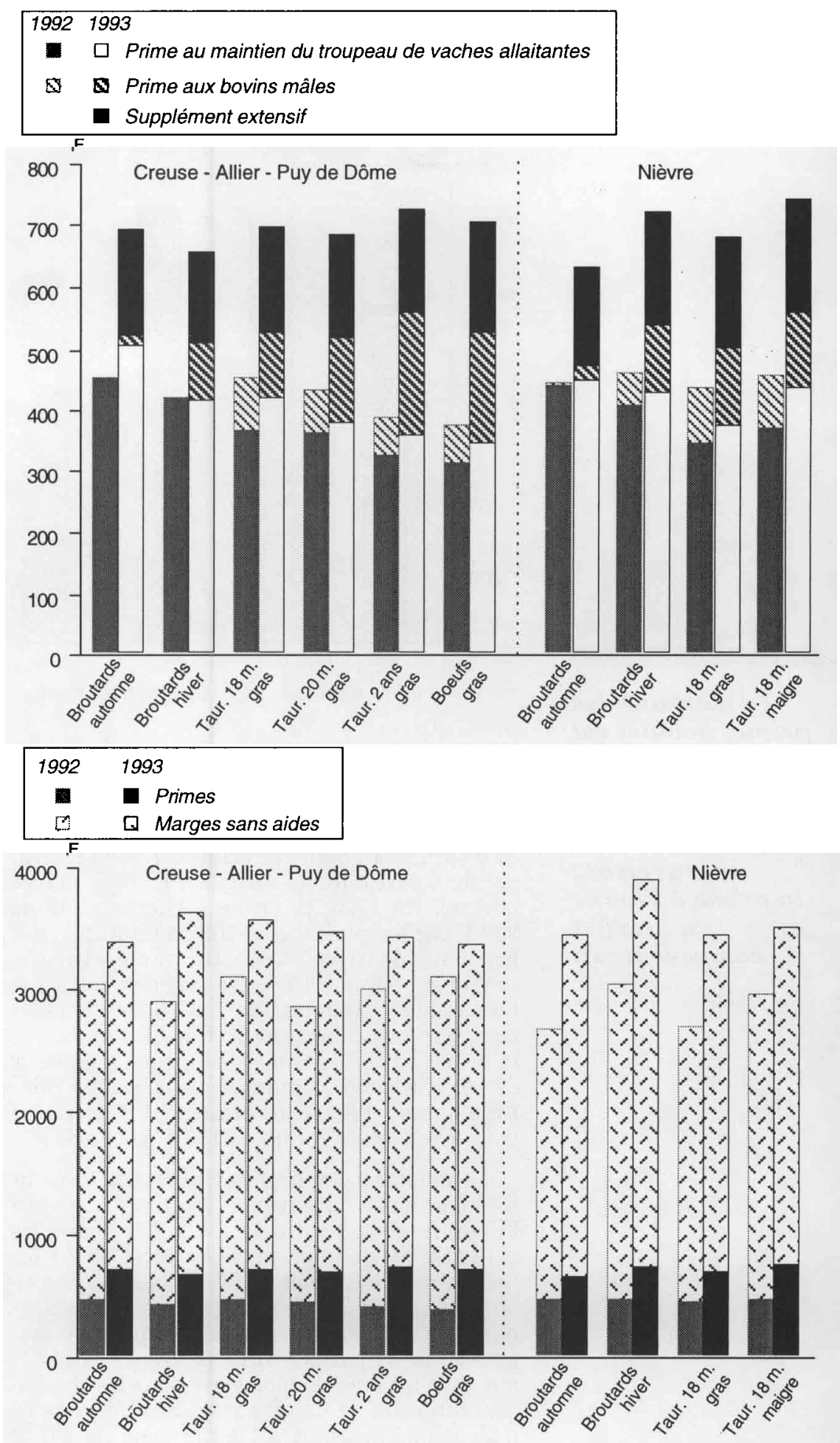

exploitations) sont indépendants des primes, avec un minimum de $3400 \mathrm{~F}$ pour les boufs et les broutards d'automne, autour de $3500 \mathrm{~F}$ pour les 18 mois maigres et les taureaux herbagers de 2 ans, et un maximum de $3800 \mathrm{~F}$ pour les taurillons d'auge de la Creuse et les broutards d'hiver de la Nièvre (figure 6). L'amplitude du montant sans les primes s'est un peu élargie par rapport à 1992.
Les augmentations des primes et des marges par $U G B$ diffèrent peu entre systèmes de production. 
Figure 7. Montant total des aides bovines, ovines, de la prime à l'herbe et au maïs fourrage par hectare de SFP en 1991 et 1993.
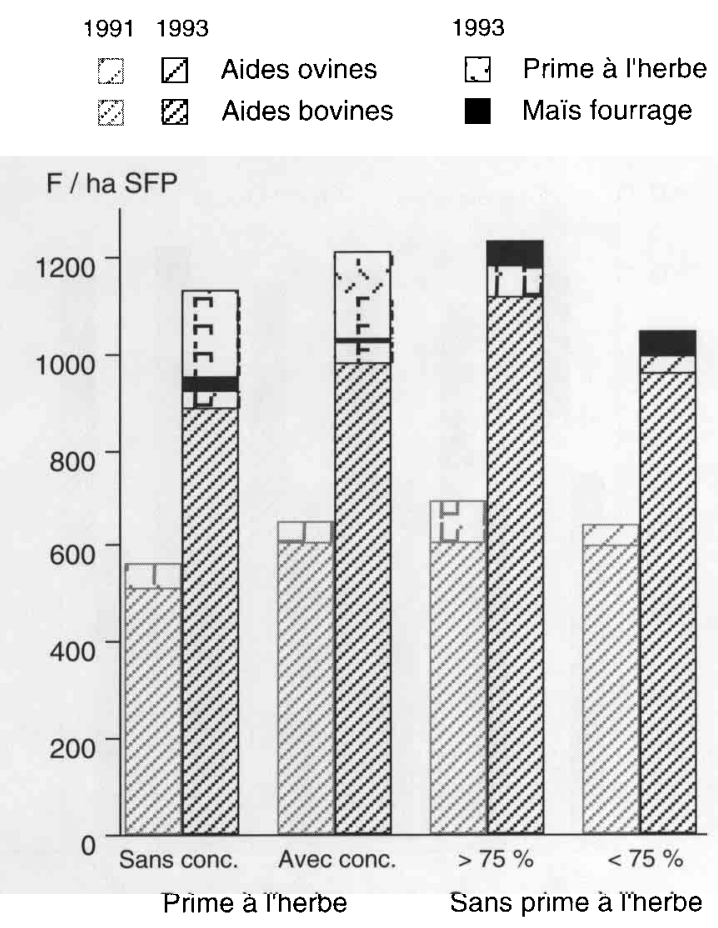

Les primes à la SFP ont aussi un effet compensateur, comme recherché. Les primes à la SFP (prime à l'herbe et prime au maïs-fourrage) font partie de la marge SFP (hors marge bovine). En 1993, la prime à l'herbe a été de $200 \mathrm{~F}$ par ha, plafonnée à 100 ha (multiplié par le nombre de parts GAEC). Dans l'observatoire, ce plafond élimine $10 \%$ des surfaces des bénéficiaires (15 exploitations sur 45 sont concernées par le plafonnement). Chez les exclus de la prime à l'herbe, le maïs est primé à hauteur de $95 \%$, soit un montant de $49 \mathrm{~F}$ par ha SFP. Finalement, l'écart de primes SFP entre les deux types est de l'ordre de $150 \mathrm{~F}$ par ha SFP.

Le montant des primes SFP est nettement inférieur à celui des primes bovines : ramené à l'UGB, il est de l'ordre de 150 à $200 \mathrm{~F}$ chez les bénéficiaires de la prime à l'herbe et $35 \mathrm{~F}$ chez les exclus, contre 650 à $700 \mathrm{~F}$ pour les primes bovines. De ce fait, le chargement reste déterminant sur le montant total (bovines, ovines, primes SFP) par ha SFP (figure 7). Ainsi le montant total est le plus élevé chez les "herbagers intensifs" (1 $226 \mathrm{~F}$ par ha SFP) bien qu'ils n'aient pas la prime à l'herbe mais ils ont le chargement le plus élevé (1,50 UGB/ha SFP). Il est le plus faible chez les "mixtes fourragescéréales" (1 038F) car ils ont un chargement plus faible $(1,33)$ sans avoir la prime à l'herbe. Les bénéficiaires de cette prime ont des montants totaux intermédiaires : $1126 \mathrm{~F}$ pour les "primes à l'herbe sans concessions" (chargement de 1,16), et $1209 \mathrm{~F}$ pour les "primes à l'herbe avec concessions" (chargement de 1,30).

Le double dispositif des primes bovines et fourragères apparaît finalement relativement compensateur. De ce fait, les écarts de marge
Figure 8. Montant de la marge de la surface fourragère par ha en 1991 et 1993.

$$
\begin{array}{cl}
1991 & 1993 \\
& \square \text { Marge brute sans aide } \\
& \square \text { Aides bovines et ovines } \\
& \square \text { Aide SFP }
\end{array}
$$

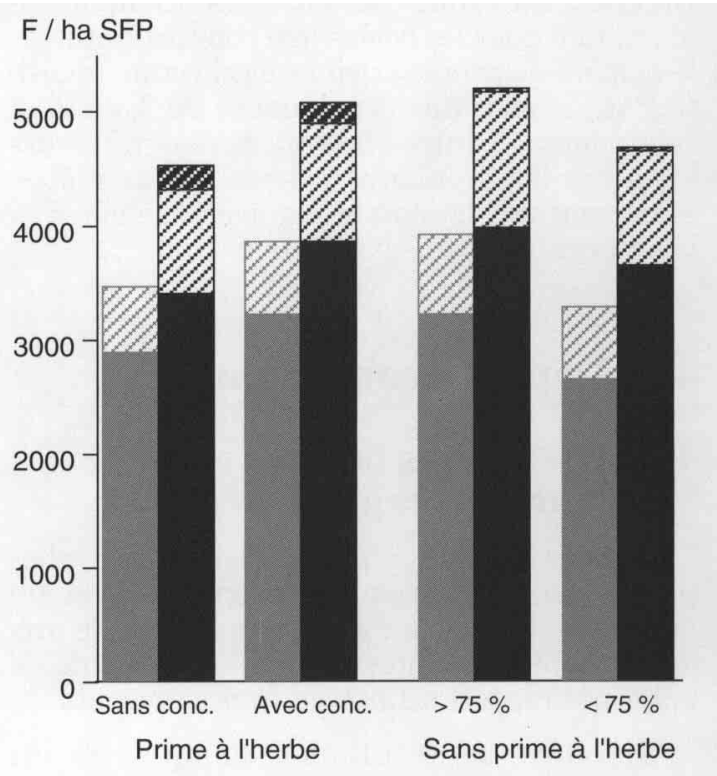

Figure 9. Montant de la marge de la surface fourragère par travailleur en 1991 et 1993.

$$
\begin{array}{ll}
1991 & 1993 \\
21 & \square \text { Aides bovines et ovines } \\
& \square \text { Aide SFP }
\end{array}
$$

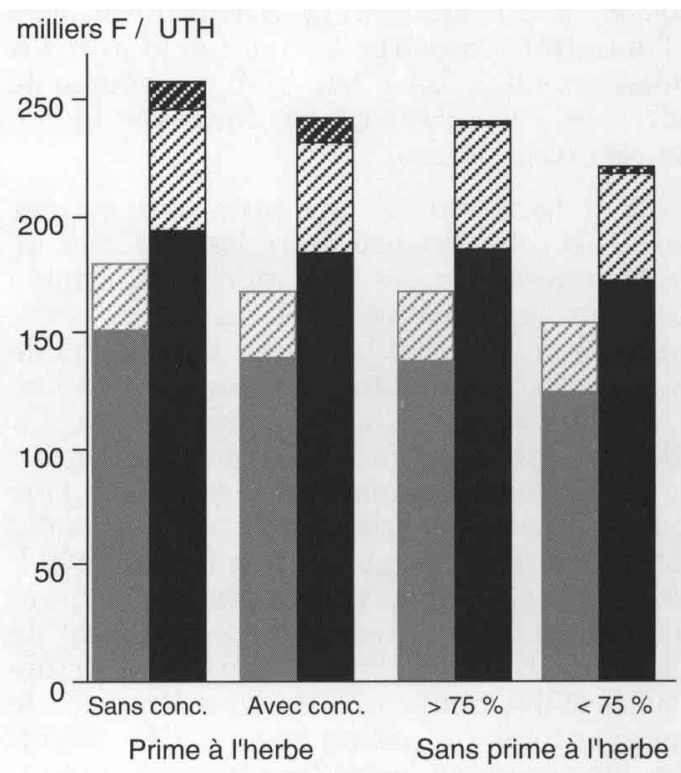

par ha SFP, et plus significativement par travailleur, restent davantage influencés par les facteurs classiques que sont l'efficacité technico-économique du troupeau, l'utilisation de la SFP et surtout l'importance des effectifs de troupeaux (figures 8 et 9). Avec l'élévation progressive du montant des aides, cette conclusion pourrait être infléchie en 1995, mais de peu sans doute. 
Figure 10. Montant des marges des cultures par ha en 1991 et 1993

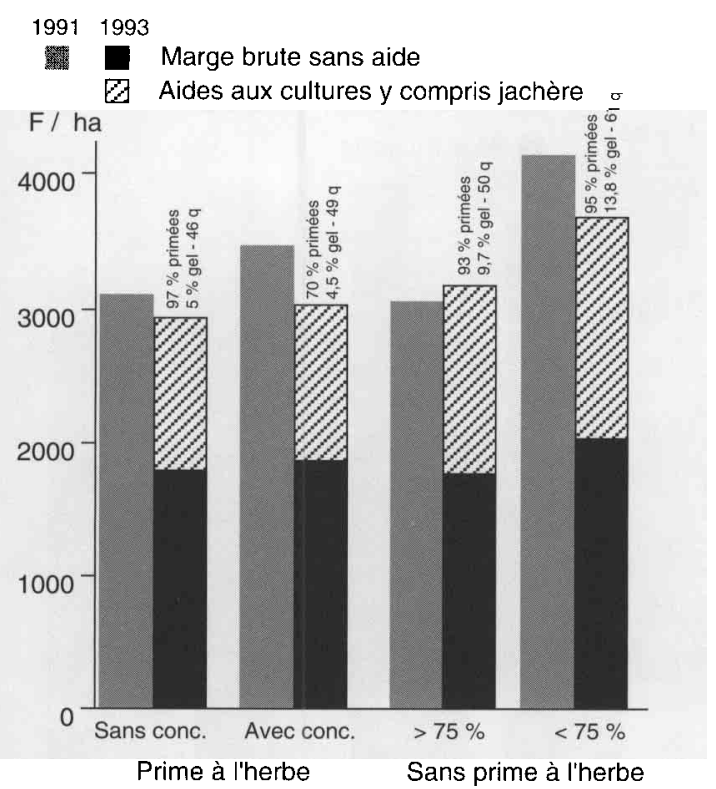

\section{2 / Les marges des cultures diminuent}

En moyenne, la marge des cultures (y compris le gel) diminue de $3690 \mathrm{~F}$ par ha en 1991 et 1992 à $3360 \mathrm{~F}$ en $1993(-9 \%)$. Les prix de vente ont baissé (d'environ 0,20 F par kg pour les céréales), mais les primes compensent, du moins pour ceux qui sont proches du rendement de référence de leur région. La réduction de la marge moyenne résulte essentiellement de la jachère (gel) et un peu de la baisse des rendements 1993 (-1 à -3 quintaux par ha, pour l'ensemble).

Comme les simulations l'avaient montré (Blogowski et Boyer 1994, Desriers et al 1994), les exploitations les plus céréalières ( $>35 \%$ de la $\mathrm{SAU}$ ) qui ont les rendements les plus élevés et supérieurs aux références de leur zone et qui doivent geler le plus, sont les plus pénalisées, avec une perte de l'ordre de $600 \mathrm{~F}$ par
Figure 11. Montant des marges des cultures par travailleur en 1991 et 1993.

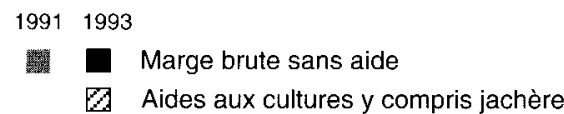

龊

0 Aides aux cultures y compris jachère

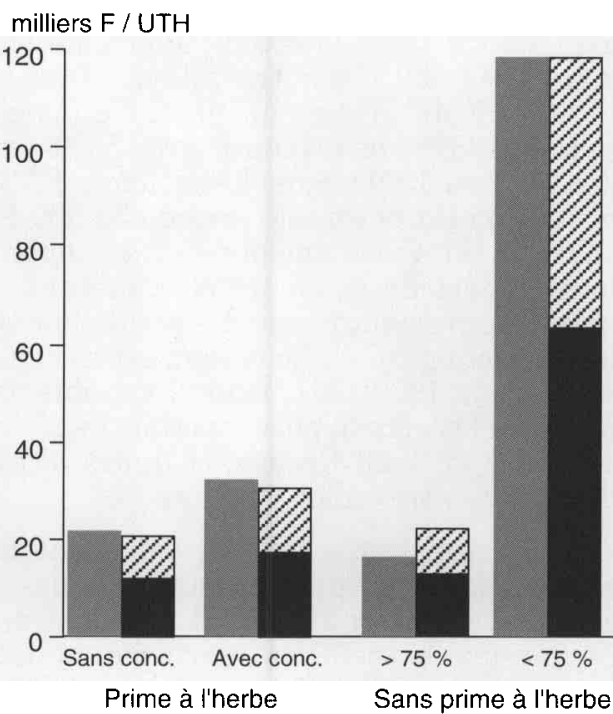

hectare de cultures (+ gel) (figure 10). Pour les plus spécialisées d'entre elles ( $>48 \%$ ) la perte atteint $35000 \mathrm{~F}$ par travailleur. Les exploitations les plus céréalières se retrouvent en majorité dans le type "mixte fourragecéréales": celui-ci perd en moyenne $12000 \mathrm{~F}$ par travailleur sur les cultures (figure 11). En revanche, la perte est limitée à moins de $3000 \mathrm{~F}$ dans les autres types. Il peut même y avoir une légère augmentation de marge lorsque les rendements sont inférieurs à la moyenne départementale, cas des "herbagers intensifs" (figures 10 et 11).

\section{3 / Un revenu meilleur, avec des écarts entre exploitations réduits}

Globalement, le montant des charges de structure est stable par hectare sur les 3 ans
En 1993, la marge des cultures diminue en moyenne de près de $10 \%$, essentiellement du fait de la jachère. Les exploitations mixtes fourragescéréales sont les plus pénalisées.

Figure 12. Marge globale et charges de structure comparatives par ha SAU en 1991 et 1993.

\section{Prime à l'herbe sans concession}

(30 exploitations)

\section{Prime à l'herbe avec concession \\ (15 exploitations)}

\section{Sans prime à l'herbe avec plus de $75 \%$ (12 exploitations)}

Sans prime à l'herbe avec moins de $75 \%$ (19 exploitations)

F/ ha SAU

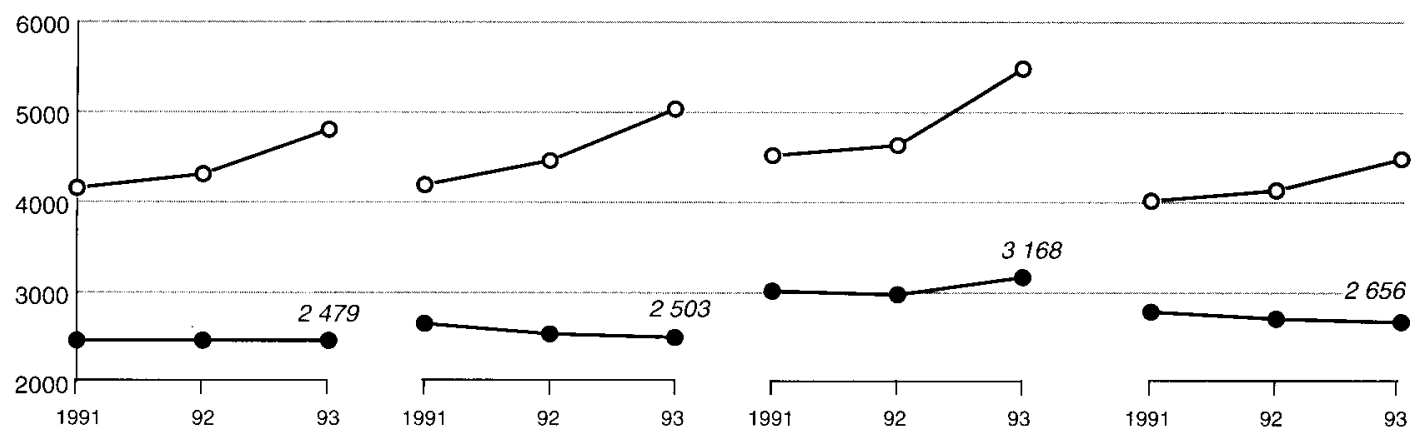

- Marge brute globale

- Charges de structure comparatives 
Entre 1992 et 1993

le revenu

augmente de $44 \%$.

constituent $68 \%$ du revenu.
Les primes

(autour de $2650 \mathrm{~F}$ en moyenne), et ceci dans la plupart des exploitations, sauf investissements nouveaux importants et/ou agravation de l'endettement. Les charges par travailleur s'alourdissent selon l'agrandissement (en moyenne + $10000 \mathrm{~F}$ par UTH) (figure 12 ).

Par rapport à 1992 , le revenu augmente en moyenne de $44000 \mathrm{~F}$ par travailleur $(44 \%)$, dont $40000 \mathrm{~F}$ de primes en plus. Celles-ci représentent $68 \%$ du revenu contre $58 \%$ en 1992 (et $64 \%$ en 1991). Sans les créances PAC l'augmentation est encore de près de $36000 \mathrm{~F}$ par UTH $(38 \%)$. Cette amélioration est forte. Sur longue période et en francs constants, 1993 fait effectivement partie des points hauts depuis 1978 (cf figure 4). Le revenu est comparable à ceux de 1980/1981, mais il est obtenu avec un cheptel beaucoup plus important $(+25 \%$ en Nièvre, $+35 \%$ en Creuse, cf figure 3 ) et plus de surface à travailler (cf figure 2).

Toutes les exploitations voient leur résultat s'améliorer, dans des proportions variables : globalement la variabilité est néanmoins réduite, puisque le coefficient de variation des revenus par travailleur $(35 \%)$ est le plus faible enregistré depuis 1978, et cela dépasse le classique effet "des bonnes années" qui réduit les différences. Par comparaison, le coefficient de variation était de $47 \%$ en 1991 , de $40 \%$ en 1992 et de $83 \%$ en 1986, année de très faibles revenus.

Ainsi, les aides ont incontestablement réduit les écarts, sans pour autant remettre en cause "l'ordre des revenus" ni modifier beaucoup les facteurs fondamentaux de leur disper$\operatorname{sion}^{(2)}$. Mais il y a une autre raison au resserrement des revenus. Les grandes exploitations bovins-céréales qui avaient auparavant les meilleurs résultats du fait de leur dimension voient leur revenu augmenter très peu et se fondre dans la moyenne ${ }^{\lfloor 3 !}$. On le voit indirectement en comparant les évolutions de revenus par type PAC : la plus faible augmentation est celle des "mixtes fourrages-céréales", où se retrouvent les plus céréalières; ils sont les seuls à voir leur revenu sans les aides diminuer entre 1991 et 1993 (figures 13 et 14).

Les augmentations de revenu les plus fortes se retrouvent chez les "herbagers intensifs". Néanmoins leurs revenus restent parmi les plus faibles. Certes l'absence de prime à l'herbe n'y est pour rien. Les plus faibles structures en sont la cause ( 54 ha par UTH, contre 58 et 64 chez les bénéficiaires de la prime à

Malgré le caractère forfaitaire des primes, les écarts de revenu dépendent toujours des résultats techniques et des effectifs du troupeau.

'21 Le facteur dimension du troupeau est renforcé, car la corrélation avec le revenu par travailleur est de $0,63(\mathrm{n}=93)$, c'est une des valeurs les plus élevées depuis 16 ans. La corrélation revenu et marge par UGB est de 0,35 , une des plus faibles (les moyennes sur 16 ans sont respectivement de 0,50 et 0,46 ). Mais il s'agit là d'un classique effet abonne année".
Figure 13. Revenu du travail et des capitaux propres d'exploitation par ha SAU en 1991 et 1993.

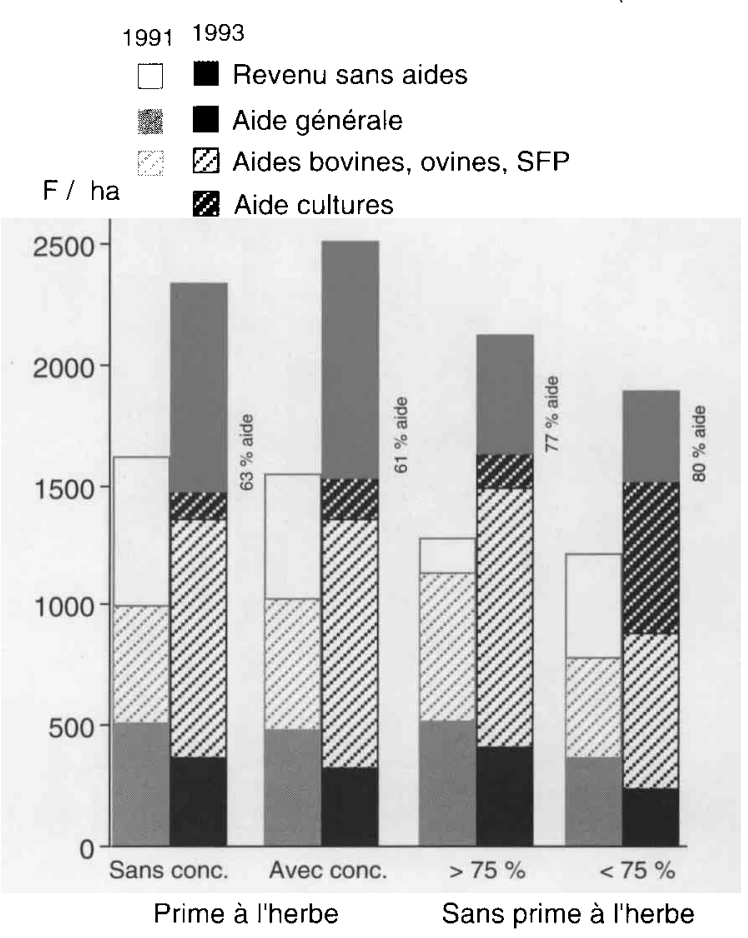

${ }^{(3)}$ En ne considérant que les 5 exploitations les plus céréalières (> $48 \%$ ), l'augmentation de revenu n'est que de $16 \%$. Mais le bouleversement majeur est que la proportion d'aides est de $109 \%$, valeur la plus élevée de tous les systèmes, contre $27 \%$ en 1991, valeur la plus faible !
Figure 14. Revenu du travail et des capitaux propres d'exploitation par travailleur en 1991 et 1993.

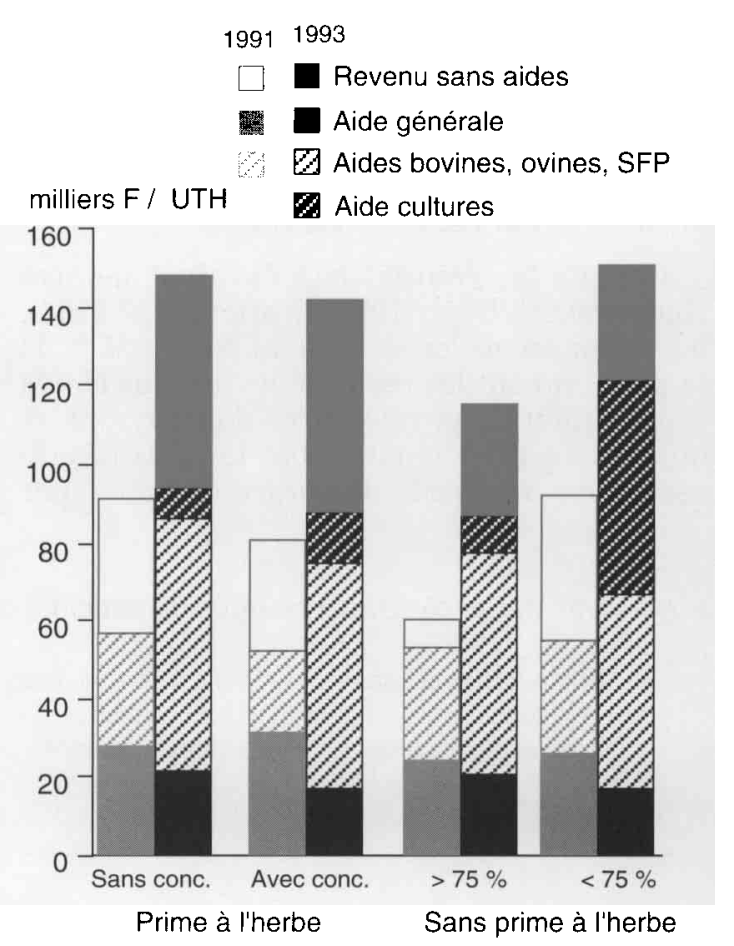
$\begin{aligned} & 1991 \\ & 1993 \\ \square & \square \text { Revenu sans aides } \\ \text { milliers F/ UTH } & \square \text { Aide générale } \\ & \square \text { Aides bovines, ovines, SFP } \\ & \square \text { Aide cultures }\end{aligned}$

l'herbe). L'intensification a permis à ces éleveurs de compenser puisque c'est là que se trouvent beaucoup de grands troupeaux par travailleur - (70 UGB par UTH en moyenne, contre 62 et 66 chez les bénéficiaires de la prime à l'herbe) - et la marge SFP par travailleur y est aussi élevée. Mais, on le sait, l'intensification entraîne des charges de structures plus lourdes, non seulement par hectare 
Figure 15. Evolution du revenu du travail et des capitaux propres d'exploitation par travailleur.

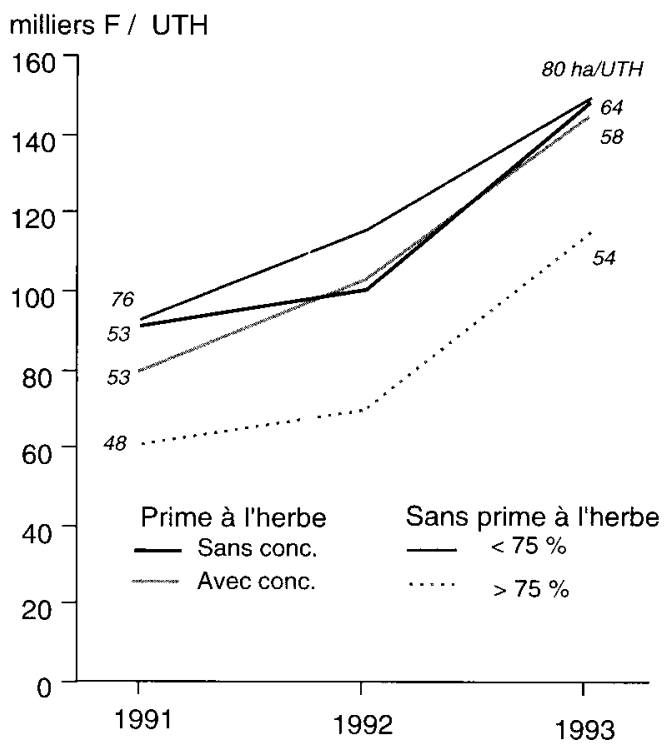

(3 $230 \mathrm{~F}$ ) mais aussi par unité de maind'œuvre ; il y a aussi un peu moins de marges diverses (céréales, aides générales) et voilà généré un déficit de 25 à $30000 \mathrm{~F}$ de revenu par travailleur par rapport aux bénéficiaires de la prime à l'herbe (figure 14) ; sur ce déficit, l'absence de prime à l'herbe ne représente que $9000 \mathrm{~F}$ par travailleur.

\section{4 / Une reprise des investissements, un désendettement}

Si on fait abstraction des "créances PAC", l'amélioration du résultat courant est de $77000 \mathrm{~F}$ par exploitation (+ $40 \%)$. La moitié de ce supplément a été investi en augmentation des capitaux propres et annuité foncière (autofinancement net), l'autre moitié a servi aux prélèvements privés et à l'épargne.

En effet, les investissements en nouveaux équipements ont repris (plus de $88000 \mathrm{~F}$ par exploitation en 1993, contre $70000 \mathrm{~F}$ en 1991 et en 1992) et ils dépassent d'un quart les amortissements, il y a croissance nette. Le cheptel et les stocks augmentent de plus de $50000 \mathrm{~F}$. En outre, il y a désendettement, les remboursements (hors foncier) excédant les nouveaux emprunts de près de $40000 \mathrm{~F}$. Au total, en ajoutant les annuités foncières $(11300 \mathrm{~F})$ et en déduisant le compte exceptionnel, la croissance des capitaux propres (autofinancement net) approche des $110000 \mathrm{~F}$ par exploitation, soit $40 \%$ du résultat courant, les $60 \%$ restant étant en épargne et prélèvements privés (pour près de 2 UTH familiales).

Par comparaison, en 1991, un quart seulement du résultat courant avait pu être investi en croissance des capitaux propres (et fonciers) soit $41000 \mathrm{~F}$ par exploitation, dont $90 \%$ ont été consacrés au désendettement et au foncier, qui constituent en quelque sorte des emplois préalables; la croissance des équipements a été nulle cette année là, comme d'ailleurs en 1992. (les nouveaux équipements ne dépassant pas les amortissements).

En définitive, cette année 1993, exceptionnelle, a permis un retour aux investissements de croissance, qui se prolongera sur 1994. Ce retour est assez général dans tous les départements de la zone où on a constaté une reprise des Plans d'Amélioration Matériels (PAM). C'est heureux, car il faut préparer un avenir sans doute moins favorable.

\section{Conclusion}

L'adaptation principale de ces éleveurs en majorité "pérennes" face à la réforme de la PAC et ses mesures d'accompagnements a été une prise de position sur l'avenir, en ce qui concerne les mesures individuelles irréversibles.

En 1992, c'est la constitution des références en primes vaches allaitantes, qui a revêtu deux formes différentes: un meilleur ajustement du troupeau aux contraintes déclaratives, avec le choix des dates (déclarationréformes), et une augmentation du troupeau de vaches. Celle-ci s'est faite principalement par croît interne, puisque ces grandes exploitations disposent d'un volant important de génisses (avantage du "système charolais"), secondairement par réduction des réformes et/ou achat de génisses pleines et surtout de vaches (comme constaté dans le réseau concerté Allier). L'effort a pu être prolongé en 1993.

La seconde préoccupation majeure a été l'obtention de la prime à l'herbe. Malgré son montant finalement modeste par rapport au reste des primes dans les conditions actuelles, c'est de la "trésorerie nette", et elle a beaucoup mobilisé les éleveurs des zones herbagères qui ont tout fait pour l'obtenir, malgré la contrainte d'un engagement de 5 ans. Car ils ont compris que c'était aussi un acquis pour 5 ans "non différable". En 1993, rien n'était connu des possibilités de pouvoir l'obtenir à nouveau pour la première fois en 1994 - cette possibilité a été très limitée dans les faits ( 5000 bénéficiaires "nouveaux", contre 120000 en 1993). L'effet est visible sur l'agrandissement en herbe, sur les chargements, sur la composition des troupeaux.

En revanche, les changements que pouvait entraîner la prime bovin mâle sur le système d'élevage n'ont pas été importants en 1993, du moins en charolais, dans les exploitations suivies. On ne peut considérer comme un véritable changement le vieillissement des broutards au-delà de 10 mois. Les modifications, s'il y en a véritablement, notamment le réallongement du cycle au-delà de 23 mois, peutêtre en partie avec des bœufs, seront pour 1995, et dépendront avant tout des marchés.

Mais on n'a évidemment pas réduit l'effectif des mâles (porteurs de primes) dans le troupeau. Et l'ajustement des troupeaux aux multiples contraintes a été finalement fait au détriment des génisses de moins de 15 mois
Les éleveurs se sont mobilisés sur la constitution de références en primes vaches allaitantes en augmentant leur troupeau, et sur l'obtention de la prime à l'herbe malgré les engagements qu'elle entraîne sur 5 ans. 
dont les ventes ont augmenté de $50 \%$ sur les deux ans. On retrouvera l'effet du déficit d'une génération de génisses sur l'augmentation des effectifs vaches de 1994/1995, mais celle-ci est désormais encadrée par les références... et les possibilités d'une croissance à plus long terme sont néanmoins sauvegardées, car, déjà en janvier 1994, les génisses de 9 mois sont plus nombreuses qu'en janvier 1991... En revanche, il est clair que l'engraissement des génisses (non primées) pourra être remis en cause, sauf s'il est envisagé, comme le font déjà certains éleveurs, avec un vêlage, qui devra désormais être accompagné d'un supplément de références. On peut s'attendre à voir les taux de réforme de certains troupeaux allaitants se différencier beaucoup dans l'avenir.

La réforme de la PAC génère des contraintes pour le développement ultérieur, effectif des troupeaux, utilisation du sol, de l'espace et des parcelles. Néanmoins les possibilités et les options vont quelque peu différer selon qu'il faudra respecter les engagements qu'impose la prime à l'herbe, ou qu'on est définitivement exclu de son bénéfice. Les premiers devront rester dans un système herbager peu intensif, qui n'exclut pas un engraissement à base d'herbe. Les seconds n'auront pas d'autres choix que de conserver un système basé sur l'intensification et souvent les cultures, avec, on peut l'espérer, le maintien de l'engraissement. Mais tous pourront être preneurs de surfaces et de références en primes vaches allaitantes supplémentaires.

Si les possibilités d'agrandissement et l'évolution des marchés restent des éléments clés de l'avenir, il s'y ajoute désormais la manière dont sera gérée la mobilité des références en primes vaches allaitantes. Celle-ci sera aussi déterminante sur l'équilibre des systèmes et plus encore sur le développement à moyen terme des exploitations et l'installation des jeunes, et au-delà sur l'aménagement du territoire départemental. Mais elle influencera aussi les décisions à court terme des éleveurs : ainsi, comment mettre à la reproduction des génisses supplémentaires alors qu'on n'a aucune certitude de pouvoir bénéficier d'attribution définitive ou même de prêt de primes l'année suivante? Faudra-t-il attendre ceux-ci pour accroître le troupeau de vaches au risque de sous utiliser pendant un an les références supplémentaires? Cette interrogation, encore peu présente, s'amplifiera avec la diminution possible des prix de vente. Plus généralement, l'espace d'incertitude s'élargit à nouveau pour chaque éleveur de vaches allaitantes, rendant ses choix et sa gestion prévisionnelle plus difficiles encore.

\section{Remerciements}

Cette étude a été réalisée avec l'aide de la CEE (FEOGA).

\section{Références bibliographiques}

Benoit M., Laignel G., Liénard G., 1993. Fragilité des élevages ovins face à la baisse des prix Incidence de la réforme de la PAC et de la prime à l'herbe. Exemple du Montmorillonnais et du Massif Central Nord. INRA-ESR, Actes et Communications $\mathrm{n}^{\circ} 10,145-165$.

Blogowski A., Pascalis C., 1993. Les effets de la réforme de la PAC sur les concours publics. Cahier $\mathrm{n}^{\circ}$ 16. Série AGRESTE, SCEES Ministère de l'Agriculture (Paris), 25-34.

Blogowski A., Boyer Ph., 1994. Les effets différenciés de la réforme de la PAC sur les revenus des agriculteurs. Economie Rurale, 220, 124-130.

Bortzmeyer M., Cavailhès J., Liénard G., 1992. Revenus et systèmes de production : l'élevage bovin dans le charolais. In : Réforme de la PAC simulations et analyses. INRA Sciences Sociales, 6 , novembre 1992.

Bousset J.P., Liénard G., 1992. Prévision de revenu et estimation de limpact de la nouvelle PAC sur le revenu de quelques systèmes de production de viande bovine. Note CEMAGREF (Riom) et Laboratoire d'Economie de l'Elevage (INRA - Theix), $26 \mathrm{p}$.
Bousset J.P., Baud G., Barlet D., Gourbeyre G., Liénard G., Lherm M., 1994. Etude technicoéconomique de 3 systèmes de production de viande bovine dans l'Allier, campagne 1992/1993. Etude concertée CEMAGREF (Riom), Chambre d'Agriculture de l'Allier (Service Economique), Laboratoire d'Economie de l'Elevage (INRA-Theix) 40 p. + annexes.

Butault J.P., Desbrosses B., Roussel J.M., Wavresky P., 1994. Situation économique des éleveurs de bovins et réforme de la PAC. Economie Rurale, 220, 136-139.

Desriers M., Perrel B., Strauss J.P., 1994. Réforme de la PAC : des aides plus favorables à l'élevage qu'aux grandes cultures ; vers une réduction des disparités géographiques de revenu. Economie Rurale, 220, 119-123.

Hairy D., de La Villosoye, 1994. Les concours publiés à l'agriculture. Une nouvelle approche : bilan sur 1991 et projections à 1996 . Etude n 28. Série AGRESTE, SCEES. Ministère de l'Agriculture (Paris), $84 \mathrm{p}$. 
Institut de l'Elevage, 1992. La réforme de la PAC et les productions bovines et ovines. Simulation et éléments d'analyse. I.E. (Paris), 26 p.

Lherm M., Bébin D., Liénard G., 1991. Les élevages de bovins allaitants spécialisés sont profondément affectés par la crise bovine. Evolution 1989/90 et à plus long terme d'un groupe d'élevages du charolais central. Première analyse sommaire. INRA, Prod. Anim. 4 (4), 328-338.
Lherm M., Bébin D., Liénard G., 1994. Evolution mensuelle du cheptel bovin présent selon le système de production. Cas des exploitations charolaises de la zone herbagère centrale. Note. Laboratoire d'Economie de l'Elevage (INRA - Theix) - $8 \mathrm{p}$.

Liénard G., Lherm M., Bébin D., Benoit M., Laignel G., 1994. Note méthodologique : conséquences de la réforme de la $\mathrm{PAC}$ sur la présentation des résultats de gestion, pour les réseaux d'observation. Laboratoire d'Economie de l'Elevage (INRA-Theix), 13 p. + annexes.

\section{Summary}

Effect of the reform of the CAP on suckling cows farms in Central Charolais.

The reform of the CAP is concerned with the suckling cows herds in their three functions : meat and crop productions, and space utilization.

We will offer a typology of situations patterned according to the modalities of the reform, which is drawn from the study of different farms.

The adaptations made in 1992 and 1993 are presen-

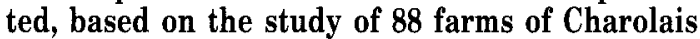
cattle, compared with the situation in 1991, and they are resituated within the context of a longterm evolution. Breeders' efforts were first focused, in 1992, on conforming to the individual quota of compensatory subsidies suckling cows, coupled with an increase in herd size. In 1993, the change in the use of land space in order to be eligible for the grassland and crop subsidies become the main concerns. Moreover while the reform affected the breeding of males only a little, the breeding of heifers (not subsidized) bose the main changes. These trends are likely to remain the same in 1995. But the main element in future development will depend on the flexibility of references in connec. tion with possible surface increases.

LHERM M., BÉBIN D., LIÉNARD G., 1994. Elevages allaitants Charolais des zones herbagères face à la réforme de la PAC. Proposition d'une typologie d'adaptations et premiers résultats 1993. INRA Prod. Anim., 7 (5), 343-357. 